\title{
TRUNCUS ARTERIOSUS REPAIR: INFLUENCE OF TECHNIQUES OF RIGHT VENTRICULAR OUTFLOW TRACT RECONSTRUCTION
}

François Lacour-Gayet, MD

Alain Serraf, MD

Tatsuiko Komiya, MD

Miguel Sousa-Uva, MD

Jacqueline Bruniaux, MD

Anita Touchot, MD

Daniel Roux, MD

Paul Neuville, MD

Claude Planché, MD
Fifty-six consecutive patients underwent total correction of truncus arteriosus. Median age at repair was 41 days, with a range of 2 days to 8 months. In $71 \%$ the operation was done in the first 2 months of life. Nine patients had complex forms of truncus and 11 patients had aortic insufficiency. The truncal aortic root was transected, which provides a clear exposure of the coronary ostia. The aorta was reconstructed by direct end-to-end anastomosis, and the truncal valve was preserved in every case. Several different techniques were used for pulmonary reconstruction, including three types of anatomic reconstruction of the pulmonary valve with a trisigmoid leaflet system and two types of nonanatomic reconstruction. The anatomic techniques included use of 33 Dacron valved conduits, eight homograft valved conduits, and one porcine aortic root bioprosthesis. The nonanatomic reconstructions included direct anastomosis to the right ventricle in nine patients and insertion of autologous pericardial valved conduits in five. The hospital mortality was $16 \%(9 / 56 ; 95 \%$ confidence limits, $2 \%$ to $30 \%$ ). Multivariate analysis outlines two independent incremental risk factors for hospital death: nonanatomic pulmonary valve reconstruction techniques and age younger than 1 month. The hospital mortality was $7.1 \%$ in the group with anatomic pulmonary valve reconstruction versus $43 \%$ in the group with nonanatomic pulmonary valve reconstruction ( $p=0.015)$. The hospital mortality was $5.7 \%$ in those older than 1 month versus $33 \%$ in those younger than 1 month of age $(p=0.04)$. There were two late deaths. The actuarial freedom from reoperation and angioplasty at 7 years was $100 \%$ for patients receiving pericardial conduits, $80 \%$ for those undergoing direct anastomosis, $77 \%$ for those receiving Dacron conduits, and only $43 \%$ for those receiving homografts $(p=0.02)$. In conclusion, anatomic reconstruction of the pulmonary valve seems important at the time of the operation, age younger than 1 month remains an incremental risk factor, and the truncal valve can be preserved. (J THORAC CARDIOvaSC SURG 1996; 111:849-56)
№ eonatal total correction with a homograft valved conduit used to reconstruct the right ventricular outflow tract $(\mathrm{RVOT})^{1-3}$ is now recognized as the optimal method of repair of truncus arteriosus. However, small homografts could be difficult or

From the Department of Pediatric Cardiac Surgery. Marie Lannelongue Hospital. Paris Sud Université, Paris, France.

Received for publication Jan. 12, 1995; accepted for publication June 12, 1995.

Address for reprints: F. Lacour-Gayet, MD, Department of Pr. Cl. Planché, Marie Lannelongue Hospital, 133 Avenue de la Résistance, 92350 Le Plessis-Robinson, France.

Copyright (c) 1996 by Mosby-Year Book, Inc.

$0022-5223 / 96 \$ 5.00+0 \quad \mathbf{1 2 / 1 / 6 7 0 3 6}$ even impossible to obtain in a number of countries, mainly because organ procurement in infancy is so limited. Furthermore, patients receiving homografts early in life are likely to require reoperation ${ }^{4,5}$ because of either deterioration by allogenic rejection or insufficient diameter with the growth of the child. Reconstruction of the RVOT with homografts might well carry a risk of reoperation similar to that of classic Dacron valved conduits ${ }^{6,7}$ and might therefore be considered to be a two-stage procedure; however, the technique has been deliberately chosen by a numbers of teams because of the surgical safety provided.

The difficulty in obtaining small homografts, in addition to our concern about the need for reopera- 


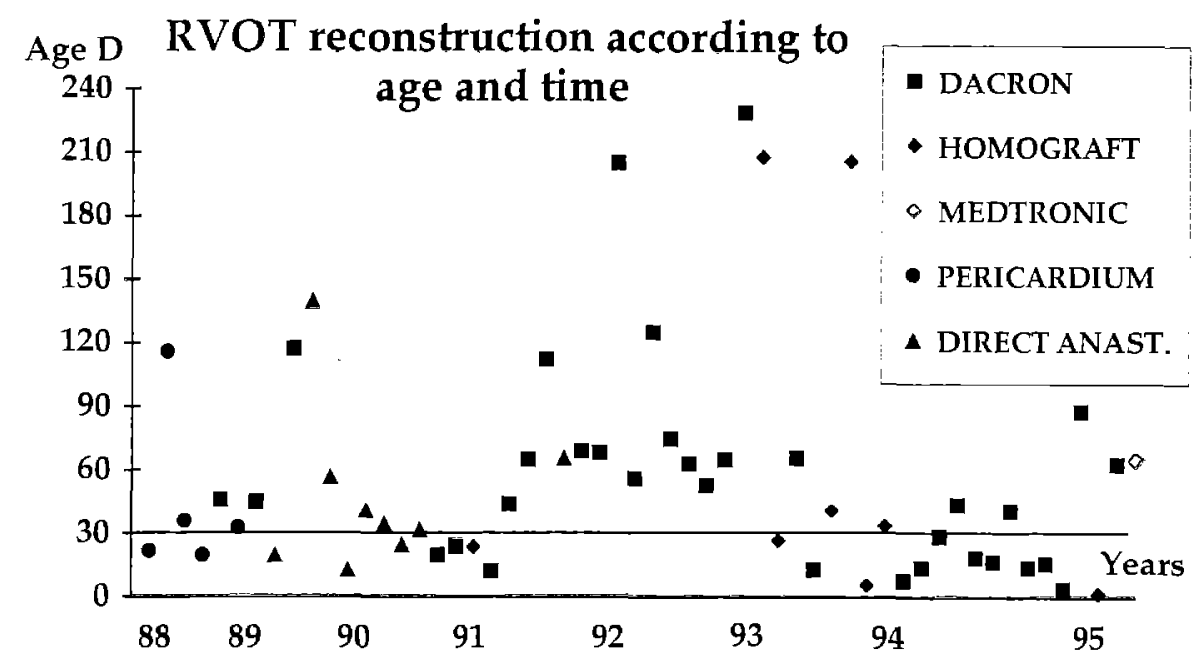

Fig. 1. RVOT reconstruction techniques according to age and years elapsed during the study. $D$, Days.

tion, has led our group to use various surgical procedures to reconstruct the RVOT. In the series presented here, the RVOT has been reconstructed with homograft valved conduits, Dacron valved conduits, direct anastomosis of the pulmonary trunk to the right ventricle, autologous pericardial valved conduits, and porcine aortic root. The purpose of this work was to study whether the type of surgical procedure used to reconstruct the RVOT has influenced the early and midterm outcome of the surgical repair.

\section{Patients and methods}

Patient population. From January 1988 to March 1995, 56 consecutive patients underwent total primary repair of truncus arteriosus. No palliative procedure was performed in the interim.

Median age at operation was 41 days, with a range of 2 days to 8 months. In $37 \%$ of the patients ( 21 patients) the operation was done in the first month of life and in $71 \%$ (39 patients) in the first 2 months of life (Fig. 1). Median weight was $3.4 \mathrm{~kg}$, with a range of 2.8 to $6.5 \mathrm{~kg}$. Eighteen percent of the patients (10 patients) weighed less than $3 \mathrm{~kg}$.

All patients were in cardiac failure and eight had required previous ventilatory support. Patients with interruption of the aortic arch received an infusion of prostaglandin $\mathrm{E}_{1}$.

According to the classification of Collet and Edwards, ${ }^{8}$ 42 patients had type I truncus arteriosus, 13 had type II, and 1 had type III. Nine patients had complex forms; seven had interrupted aortic arch, associated with truncal dextroposition and restrictive ventricular septal defect (VSD) in one patient; the two last patients had a nonconfluent left pulmonary artery for one and a complete atrioventricular septal defect for the other.

Eleven patients had significant aortic insufficiency, including nine with moderate regurgitation and two with severe regurgitation. Two patients had truncal stenosis, associated with pulmonary branch hypoplasia in one. No severely abnormal coronary artery patterns were observed.

Fifteen patients had associated di George syndrome, including six with the complete form and nine with the partial form.

Surgical technique. The operation was performed through a median sternotomy. Cardiopulmonary bypass (CPB) was conducted with full-flow perfusion ${ }^{9}$ in 49 patients and with periods of circulatory arrest in seven patients who had associated interruption of the aortic arch. The CPB machine was primed with $500 \mathrm{ml}$ of irradiated whole blood and equipped with a membrane oxygenator. Myocardial protection was achieved by either blood or a crystalloid cardioplegic solution, infused every 30 minutes. The mean crossclamp time was 64 minutes (range 31 to 78 minutes). The mean CPB time was 130 minutes (range 82 to 240 minutes). The mean circulatory arrest time, for the seven patients having circulatory arrest, was 37 minutes (range 17 to 55 minutes).

The conotruncal VSD was closed through a right vertical ventriculotomy with a running suture. The patent foramen ovale was left open in one third of the patients. A generous aortic button, containing either the pulmonary trunk in type I or the pulmonary bifurcation in type II, was resected. More recently, the aorta has been transected (Fig. 2) to provide a clearer approach to the pulmonary branches orifices and to the coronary ostia. This aortic transection allows the pulmonary bifurcation to be fully dissected. The bifurcation can then be mobilized to the left side of the aorta to allow a safer anastomosis of the distal pulmonary bifurcation, particularly in type II truncus arteriosus. The coronary ostia can be easily identified, so that the risk of coronary injuries is limited. The aortic wall defect created by the pulmonary trunk resection was repaired either by direct suture or by a patch alternatively made of Dacron polyester or tanned autologous pericardium or aortic autograft taken from the right wall of the truncal tissue. We have found it useful to resect a piece of 
the distal aorta or of the truncal wall not merely to correct the irregularities of the aortic sections but mainly to reduce the length of the ascending aorta. This resection allows the creation of an upward traction on the truncal commissures, when the direct aortic anastomosis is completed, that corrects the natural prolapse of the truncal sigmoid leaflets. No truncal valve replacement was ever performed in this series and no major coronary artery anomaly was ever recognized.

In two patients with type II truncus arteriosus, a Lecompte maneuver ${ }^{10}$ was performed to bring the pulmonary bifurcation in front of the aorta.

The RVOT reconstruction involved five different techniques, which can be divided into two groups according to the type of pulmonary valve (PV) reconstruction used. In one group (42 patients) a trisigmoid leaflet system, designated anatomic reconstruction of the $P V$, was used; this included Dacron valved conduits, homografts, and aortic root bioprostheses. In the other group (14 patients) a nontrisigmoid leaflet system, designated nonanatomic reconstruction of the $P V$, was used; this included direct anastomoses to the right ventricle and autologous pericardial valved conduits.

A Dacron polyester porcine valved conduit was used in 33 patients: 24 Hancock conduits, 22 size $12 \mathrm{~mm}$ and 2 size $14 \mathrm{~mm}$ (Medtronic, Inc., Minneapolis, Minn.), and 9 Carpentier-Edwards conduits, 8 size $12 \mathrm{~mm}$ and 1 size 14 mm (Baxter Healthcare Corp., Edwards Division, Santa Ana, Calif.). Recently the Dacron conduit has been tailored very short at both ends, leaving only the valve itself and removing the metallic ring of the Hancock conduit. The conduit is anastomosed to the infundibulotomy either directly or, more recently, with an additional hood of fresh or tanned autologous pericardium that is more suitable for performing the anastomosis to the fragile neonatal right ventricle. The conduit is placed into the left pleural cavity, which is opened wide.

A cryopreserved homograft valved conduit, including four aortic and four pulmonary homografts, was used in eight patients.

A Freestyle porcine aortic root bioprosthesis, manufactured by Medtronic, was inserted in the latest patient with the permission of the university ethics committee.

A direct anastomosis to the right ventricle, according to the technique described by Barbero-Marcial and associates, ${ }^{11}$ was performed in nine patients. The RVOT reconstruction was completed with a monocusp patch made either of homograft or xenograft tissue.

A fresh autologous pericardial valved conduit, according to the technique described by Schlichter and Kreutzer, ${ }^{12}$ was placed in five patients. The entire anterior pericardium is harvested at the beginning of the operation and a surgical assistant fashions the pericardial conduit equipped with a bicuspid valve. The diameters of the pericardial conduits ranged from 10 to $12 \mathrm{~mm}$.

The type of RVOT reconstruction technique used has evolved with time (Fig. 1); the pericardial conduits and direct anastomosis techniques were used only in the early part of the study, whereas Dacron valved conduits, homografts, and porcine aortic root were the only techniques used after 1992.

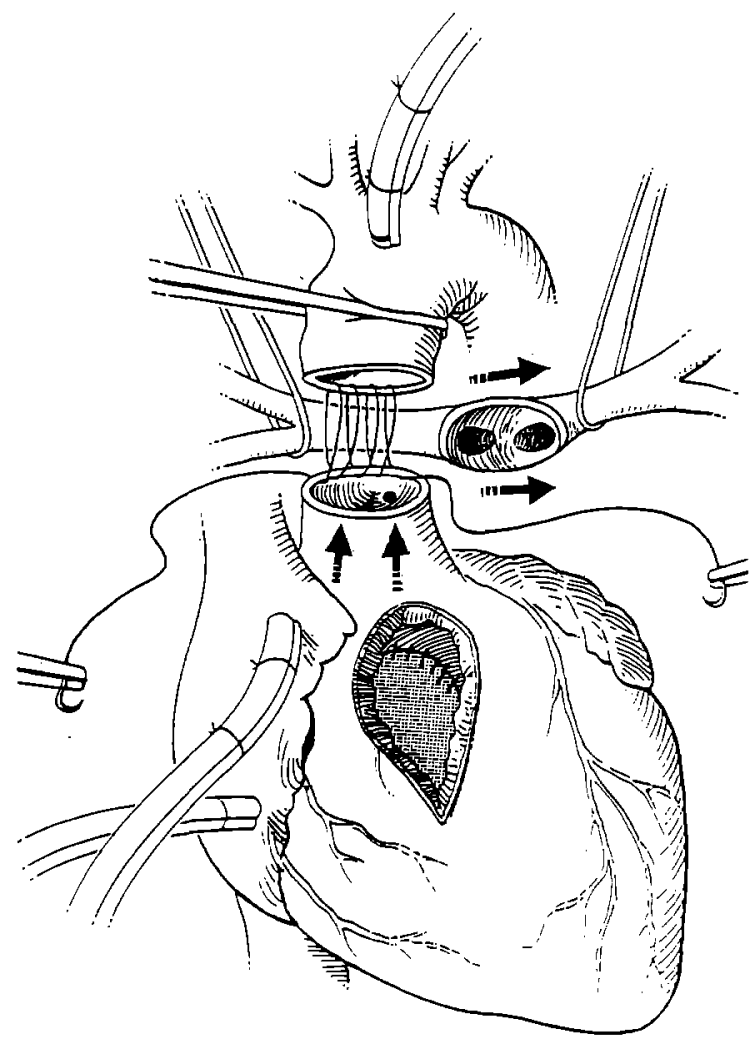

Fig. 2. Transection of the truncal aortic root provides a clear exposure of the coronary ostia that limits the risk of coronary artery injuries. The right pulmonary branch can be fully dissected and mobilized to the left in types II. The aorta is reconstructed by direct end-to-end anastomosis after equalization of the aortic transection line. This allows upward traction on the truncal commissures that might help to correct the potential tendency of aortic regurgitation by commissural prolapse.

Aortic arch repair, for the seven patients with associated interruption of the aortic arch, was completed by an extended end-to-end anastomosis ${ }^{13}$ in four patients, associated in two cases with patch enlargement of the transverse arch. In the remaining three patients, the aortic continuity was reconstructed with a $10 \mathrm{~mm}$ polytetrafluoroethylene* prosthesis because of difficult mobilization of the descending aorta. The VSD was enlarged in a patient with interrupted aortic arch, truncal dextroposition, and restricted VSD. A left pulmonary artery arising from the descending aorta was connected to the pulmonary trunk with a $6 \mathrm{~mm}$ polytetrafluoroethylene prosthesis in one patient with type III truncus arteriosus. An associated complete atrioventricular septal defect type $\mathrm{C}$, in a patient with normal karyotype, was repaired at the same time. ${ }^{14}$

Pulmonary artery pressure was monitored in the postoperative course, in all patients but four, with a pulmonary

*Gore-Tex graft, registered trademark of W. L. Gore \& Associates, Inc., Elkton, Md. 
Table I. Early mortality according to RVOT techniques

\begin{tabular}{lcccc}
\hline & No. of & \multicolumn{2}{c}{ Early mortality } & \\
\cline { 3 - 4 } & patients & $\%$ & No. & \\
\hline All patients & 56 & 16.1 & $9 / 56$ & $p=0.0015$ \\
Anatomic PV reconstruction & 42 & 7.1 & $3 / 42$ & $p=0.015$ \\
Dacron valved conduit & 33 & 6 & $2 / 33$ & \\
Cryopreserved homograft valved conduit & 8 & 12.5 & $1 / 8$ & \\
Aortic root bioprosthesis & 1 & 0 & $0 / 1$ & \\
Nonanatomic PV reconstruction & 14 & 42.8 & $6 / 14$ & 0.01 \\
Direct anastomosis on the RV & 9 & 44.4 & $4 / 9$ & \\
Autologous pericardial valved conduit & 5 & 40 & $2 / 5$ & \\
\hline
\end{tabular}

Table II. Causes of early deaths

\begin{tabular}{lcll}
\hline \multicolumn{1}{c}{ Diagnosis } & Age at repair (days) & RVOT technique & \multicolumn{1}{c}{ Causes of death } \\
\hline Truncus type I & 24 & Direct anastomosis & Low cardiac output \\
Truncus type I & 20 & Direct anastomosis & Pulmonary hypertensive crises \\
Truncus type I & 88 & Direct anastomosis & Pulmonary hypertensive crises \\
Truncus type I & 24 & Dacron valved conduit & Right ventricular dissecting hematoma \\
Truncus type II & 17 & Dacron valved conduit & Bacterial pneumopathy \\
Truncus type I & 16 & Homograft & Right ventricular pericardial patch aneurysm \\
Truncus type I with IAA & 2 & Pericardial conduit & Low cardiac output \\
Truncus type I with IAA & 66 & Pericardial conduit & Pulmonary hypertensive crises \\
Truncus type I with IAA & 12 & Direct anastomosis & Low cardiac output \\
\hline
\end{tabular}

$I A A$, Interruption of the aortic arch.

*Association with restrictive VSD and truncus dextroposition.

artery catheter introduced into the right ventricle during the operation. Pulmonary hypertensive crises were prevented by deep sedation along with different drugs, including isoprenaline, prostaglandin $\mathrm{E}_{1}$, prostaglandin $\mathrm{I}_{2}$, and more recently nitric oxide.

Statistical comparisons were performed by standard techniques for univariate analysis and by stepwise logistic regression for multivariate analysis using SPSS software (SPSS, Inc., Chicago, Ill.). Time-related events were examined by Kaplan-Meier actuarial methods. Ratios were expressed with $95 \%$ confidence limits.

\section{Results}

Hospital mortality. The hospital mortality (Table I) was $16 \%(9 / 56 ; 95 \%$ confidence limits, $2 \%$ to $30 \%$ ) in the group as a whole and as follows in the respective groups: $6 \%(2 / 33)$ in the Dacron conduit group, $12.5 \%(1 / 8)$ in the homograft group, $0 \%(0 / 1)$ in the patient having an aortic root bioprosthesis, $44 \%$ (4/9) in the direct anastomosis group, and $40 \%$ $(2 / 5)$ in the autologous pericardium group. Hospital deaths (Table II) have been attributed to the following causes: uncontrollable pulmonary hypertensive crises in three patients, severe myocardial failure in three patients, dissecting hematoma of the right ventricle in one patient, aneurysm of the pericardial ventricular patch complicated by acute right ventricular dysfunction in one patient, and bacterial pneumonitis in one patient.

Hospital mortality was studied for the following possible risk factors: age, age less than 1 month, gender, weight, weight less than $3 \mathrm{~kg}$, preoperative ventilatory support, interruption of the aortic arch, complexity, presence of truncal valve regurgitation, RVOT techniques, anatomic versus nonanatomic PV reconstruction, postoperative $\mathrm{PV}$ regurgitation, crossclamp time, years 1988 to 1991 versus 1992 to 1995, and di George syndrome.

The significant risk factors for hospital mortality according to univariate analysis are listed in Table III.

Multivariate analysis by logistic regression (Table III) shows that of eight factors deemed significant on univariate analysis, only two independent significant incremental risk factors remain: nonanatomic PV reconstruction ( $p=0.015$ ) and age less than 1 month $(p=0.04)$.

The hospital mortality associated with the different techniques of $\mathrm{PV}$ reconstruction was $7 \%$ in the group with anatomic PV reconstruction (2/33 in the Dacron valve group, $1 / 8$ in the homograft group, and $0 / 1$ in the patient with an aortic root bioprosthesis) 
and $43 \%$ in the group with nonanatomic PV reconstruction (4/9 in the direct anastomosis group and $2 / 5$ in the pericardial conduit group). These values differ at the $p=0.0015$ level.

The diagnosis of postoperative PV regurgitation was made either on the basis of the diastolic value of the pulmonary artery pressure monitored by the pulmonary artery line or on the basis of echocardiography. No PV regurgitation was noticed in the group having anatomic PV reconstruction (0/41), whereas eight patients $(8 / 14)$ in the group having nonanatomic PV reconstruction had significant PV regurgitation. The hospital mortality was $10.4 \%(5 / 48)$ for patients without PV regurgitation versus $50 \%(4 / 8)$ for patients with PV regurgitation $(p=0.005)$.

The hospital mortality was $5.7 \%$ for patients older than 1 month of age versus $33 \%$ for patients younger than 1 month of age $(p=0.04)$.

Follow-up. Follow-up information, always including echocardiograms, was obtained by contacting the referring pediatric cardiologists. No patient was lost to follow up. The mean duration of follow-up was $38 \pm$ 22 months and the range was 2 months to 7 years.

Late deaths. There were two late deaths. One death occurred at 2 months in a patient with hypoplastic pulmonary arteries in whom pressure in the right ventricle remained elevated. The other late death occurred suddenly at 9 months in the patient with nonconfluent pulmonary arteries. The actuarial survival at 7 years for all patients was $80 \% \pm 10 \%$ (Fig. 3): $88 \%$ for the Dacron conduit group, $88 \%$ for the homograft group, $60 \%$ for the pericardial conduit group, $56 \%$ for the direct anastomosis group, and $100 \%$ for the single patient with a porcine aortic root.

Reoperations. During the follow-up period, among 47 hospital survivors, 12 patients required six reoperations and six balloon angioplasties for 10 RVOT stenoses (occurring six times at the site of the PV and four times at the site of pulmonary bifurcation), one aneurysm of a nontanned ventricular pericardial patch, and one ascending aortic stenosis. None of the patients died at reoperation. The actuarial freedom from reoperation and angioplasty at 7 years was $76 \% \pm 10 \%$ for the group as a whole. Assessed according to the different techniques used for RVOT reconstruction (Fig. 4), these figures were as follows: $100 \%$ for the pericardial conduits, $80 \%$ for the direct anastomoses, $77 \%$ for the Dacron conduits, $43 \%$ for the homografts ( $p=$ 0.02 ), and $100 \%$ for the single patient with a porcine aortic root.
Table III. Incremental risk factors for hospital death $(p<0.05)$

\begin{tabular}{ll}
\hline & $p$ Value \\
\hline Univariate analysis & \\
Nonanatomic PV reconstruction & 0.0015 \\
Postoperative PV regurgitation & 0.005 \\
Age <30 days & 0.006 \\
Direct anastomosis technique & 0.01 \\
Techniques other than Dacron valved conduit & 0.015 \\
Preoperative ventilatory support & 0.02 \\
Weight <3 kg & 0.02 \\
Associated IAA & 0.04 \\
Multivariate analysis & \\
Nonanatomic PV reconstruction & 0.015 \\
Age <30 days & 0.04 \\
\hline
\end{tabular}

Multivariate analysis shows that the use of the homograft valved conduit is a statistically significant incremental risk factor for early reoperation $(p=$ 0.02 ).

No patient required early or late replacement of the truncal valve.

\section{Discussion}

This retrospective study started in January 1988, when a policy of early repair in the first 2 months of life was begun at our institution because of our previous experience, ${ }^{15}$ in which significant hospital mortality and morbidity were attributed to pulmonary vascular reactivity disorders. In this series, only nine of 56 patients $(16 \%)$ were operated on after 3 months of age because of late referral, and $71 \%$ were operated on in the first 2 months of life.

If this series is similar to other series recently published in terms of patient population and mortality, ${ }^{1-3}$ it is different in three aspects: the absence of truncal valve replacement, the absence of severely abnormal coronary patterns, and the variety of RVOT reconstruction techniques used.

No truncal valve replacement was necessary in this consecutive series, either initially or in the follow-up period, and the truncal valve could always been preserved even in the 11 patients with aortic regurgitation. The technique used here with direct suture of the aorta associated with an aortic wall resection produces an upward traction that resuspends the truncal valve commissures. We suspect that the use of too large a patch to reconstruct the aortic wall might itself promote aortic regurgitation. In the follow-up period, most of the patients have a mild to moderate aortic regurgitation that seems to 


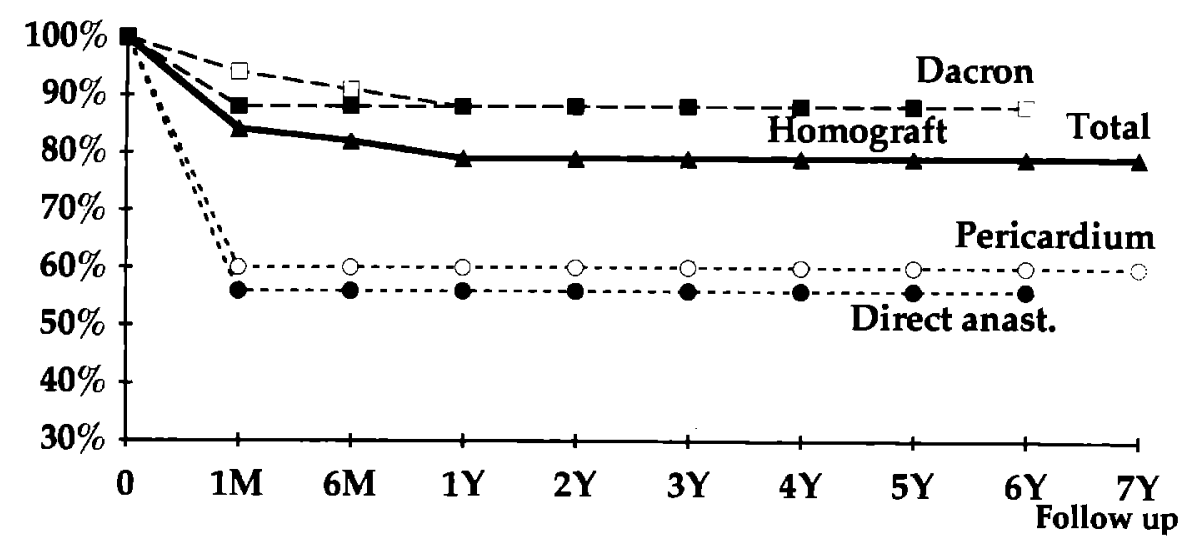

Fig. 3. Actuarial survival curves according to RVOT techniques. $M$, Month; $Y$, year.

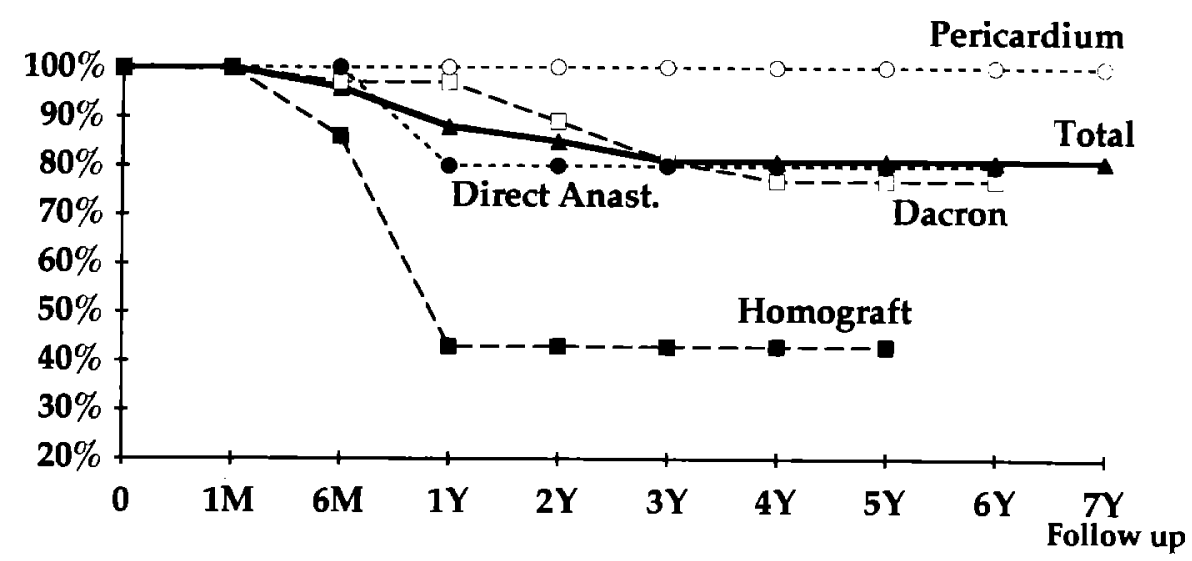

Fig. 4. Actuarial freedom from reoperation according to RVOT techniques. $M$, Month; $Y$, year.

remain stable with time. However, none of the patients in this consecutive series had the massive truncal valve regurgitation that has been observed by others. ${ }^{2,3}$ Nevertheless, preservation of the truncal valve is not associated in this study with an increased mortality, and it allows the eventual truncal valve replacement to be delayed until RVOT conduit revision becomes mandatory.

Coronary artery anomalies have been described in truncus arteriosus. ${ }^{16,17}$ In this series the coronary artery patterns have never been a cause of failure. Transection of the truncal aortic root, now used in our technique, offers excellent exposure of the left coronary ostium, which at times was found to be close to the pulmonary trunk. This safe approach may have reduced the risk of coronary injuries. In some instances an infundibular coronary artery branch had to be sacrificed, but this did not cause any major problem.
The choice of an RVOT technique is based primarily on the safety provided for the immediate results but also on the midterm and long-term results and on the availability and the cost of the different materials used.

The results of multivariate analysis give two independent significant risk factors for hospital death: the use of a nonanatomic PV reconstruction technique and age less than 1 month. Management of truncus arteriosus in the immediate postoperative course has been marked in our experience by a high risk of pulmonary hypertensive crises, which occurred typically in an unpredictable way, even in neonates. Although postoperative PV regurgitation is a significant risk factor at univariate analysis in this study, it is not a risk factor at multivariate analysis. This reflects the absence of correlation between postoperative PV regurgitation and early mortality observed in some patients who survived 
the operation despite obvious PV insufficiency. Nevertheless, the presence of a competent PV seems important for the right ventricle to overcome a pulmonary hypertensive crisis. Repair by direct anastomosis of the pulmonary trunk to the right ventricle was attempted by Lecompte and associates $^{10}$ in four patients with $50 \%$ hospital mortality; the two deaths were attributed to massive pulmonary regurgitation occurring despite the use of a monocusp xenograft valve. Repair with a valveless conduit made of polytetrafluoroethylene has been published by Spicer and colleagues ${ }^{18}$ in seven patients, with a $28.5 \%$ hospital mortality. BarberoMartial and coworkers ${ }^{11}$ published a modified technique of direct anastomosis in which they used a xenograft monocusp valve in a series of seven patients, with $14 \%$ mortality. These attempts at direct anastomosis have not been followed so far by numerous surgical groups. The majority of investigators, like those in our institution after 1992, preferred an RVOT technique that produced a perfectly competent PV. However, this study is not able to prove that $\mathrm{PV}$ regurgitation per se is an incremental risk factor for early mortality. It does establish that using an RVOT reconstruction technique that leaves a potential risk of PV regurgitation is undoubtedly an incremental risk factor.

Age less than 1 month remains a significant risk factor at multivariate analysis in this series. Associated interruption of the aortic arch, preoperative ventilatory support, and weight less than $3 \mathrm{~kg}$ are significant risk factors at univariate analysis and reflect the increased difficulties met in the neonatal group. By contrast, age older than 1 month is associated with a mortality reduced to $5.7 \%$. The use of nitric oxide in our recent experience has considerably reduced the morbidity related to pulmonary vascular reactivity disorders, previously observed in patients older than 1 month of age.

Insertion of a cryopreserved homograft valved conduit has become the most widely reported technique for RVOT reconstruction. ${ }^{1-3}$ The early mortality observed here with the homograft is in the range published in other series. On the other hand, the freedom from reoperation or balloon angioplasty was only $43 \%$ at 5 years, which seems high but corresponds to other disappointing midterm results with allografts as published by others. ${ }^{4,5,19}$ The use of a homograft is correlated in this study with an incremental risk for early reoperation $(p=0.02)$ The main reason for not using homografts in most patients in our series has been, in fact, the unavail- ability of small homografts, the difficulties resulting from limited organ donation in the infant age group and from the high cost. These limitations might be a problem in other institutions as well and led our group to use alternative methods of RVOT reconstruction.

Dacron valved conduits, size 12 or $14 \mathrm{~mm}$, were used in the majority of the patients (33/56). In this study, this technique yielded the lowest early surgical mortality $(6 \%, 2 / 33)$ that is significant at univariate analysis. The main surgical difficulty with this material is the stiffness of the Dacron polyester graft, particularly at the site of the proximal anastomosis to the fragile neonatal right ventricle. Recently, the valved conduit has been tailored so as to keep only the PV, and the gap between the valve and the right ventricle is reconstructed with a patch of tanned autologous pericardium. By means of this technique with a $12 \mathrm{~mm}$ conduit, all truncus malformations could be repaired, even in patients weighing less than $3 \mathrm{~kg}$. Freedom from reoperation at 6 years is $77 \%$, and later reoperations will be mandatory. This technique is the technique currently used at our institution when a small homograft is not available.

Direct anastomosis using the technique described by Barbero-Martial was associated with a $48.8 \%$ hospital mortality (4/9) and carries a significantly higher risk of early mortality. The high mortality observed in this group correlates with more complex anomalies. The freedom from reoperation at 6 years was $80 \%$, with one patient undergoing reoperation for stenosis of the pulmonary bifurcation in relation to the patch placed to separate the aortic and pulmonary blood flows.

The fresh autologous pericardial valved conduit was associated with a $40 \%$ hospital mortality (2/5). Significant pulmonary regurgitation was observed in the two patients who died. It is interesting to note that the freedom from reoperation at 6 years in this group is $100 \%$. However, only three patients are available for follow-up. It seems that the autologous pericardial conduit is able to grow with time. This inexpensive technique of RVOT reconstruction has the best midterm follow-up results, although associated with a high hospital mortality that is believed to be related to a poor competence of the bileaffet valve.

Very recently, a porcine aortic root bioprosthesis was inserted in a neonate. This material appears to be highly suitable and has the advantage of being permanently available in small sizes, but its midterm and long-term behavior is unknown in this age group. 


\section{Conclusion}

1. Anatomic reconstruction of the PV is essential at the time of repair.

2. Age less than 1 month remains an incremental risk factor.

3. Dacron valved conduits remain a satisfactory alternative for RVOT reconstruction.

4. Homograft valved conduits carry a higher risk of early reoperation than other reconstruction techniques.

5. Conduits constructed of fresh autologous pericardium provide excellent midterm results.

6. Transection of the truncal aortic root offers a safe approach to the coronary ostia, which limits the risk of coronary artery injury.

7. Preservation of the truncal valve does not yield an increased surgical risk.

\section{REFERENCES}

1. Pearl JM, Laks H, Drinkwater DC, et al. Repair of truncus arteriosus in infancy. Ann Thorac Surg 1991;5:780-6.

2. Hanley FL, Heinemann MK, Jonas RA, et al. Repair of truncus arteriosus in the neonate. J THORAC CARDIOVASC SURG 1993;105:1047-56.

3. Bove EL, Lupinetti FM, Pridjian AK, et al. Results of a policy of primary repair of truncus arteriosus in the neonate. J Thorac Cardiovasc Surg 1993;105:1057-66.

4. Cleveland DC, Williams WG, Razzouk AJ, et al. Failure of cryopreserved homograft valved conduits in the pulmonary circulation. Circulation 1992;86(Suppl):II150-3.

5. Hawkins JA, Bailey WW, Dillon T, Schwartz DC. Midterm results with cryopreserved allograft valved conduits from the right ventricle to the pulmonary arteries. J THORAC CARDIOVASC SURG 1992;104:910-6.

6. Griepp RB, Stinson EB, Shumway NE. Surgical correction of types II and III truncus arteriosus. J THORAC CARDIOvasC SuRG 1977;73:345-52.

7. Ebert PA, Turley K, Stanger P, et al. Surgical treatment of truncus arteriosus in the first six months of life. Ann Surg 1989;200:451-6.

8. Collet RW, Edwards JE. Persistent truncus arteriosus: a classification according to anatomical types. Surg Clin North Am 1948;29:1245.

9. Lacour-Gayet F, Nicolas F, Coll J, et al. Continuous perfusion without hemodilution in neonates. Cardiol Young 1993; 3:340-6.

10. Lecompte Y, Neveux JY, Leca F, et al. Reconstruction of the pulmonary outflow tract without prosthetic conduit. J THORAC CARDIOVASC SuRg 1982;84:722-33.

11. Barbero-Marcial M, Riso A, Atik E, Jatene A. A technique for correction of truncus arteriosus types I and II without extracardiac conduits. J THORAC CARDIOVASC SURG 1990;99: 364-9.

12. Schlichter AJ, Kreutzer GO. Autologous pericardial valved conduit. Rev Latina Cardiol Cir Cardiovasc Infantil 1985;1: 43-8.

13. Lacour-Gayet F, Bruniaux J, Serraf A, Chambran P, Blaysat G, Planché C. Hypoplastic transverse arch and coarctation in neonates. J Thorac Cardiovasc Surg 1990;100:808-16.

14. Sousa-Uva M, Lacour-Gayet F, et al. Repair of truncus arteriosus and complete atrioventricular canal defect. J THORAC CARDIOvasC SuRg 1994;108:385-7.

15. Losay J, Planché C, Lacour-Gayet F, Touchot A, Bruniaux J. Early and mid term results of truncus arteriosus repair in the first year of life. Arch Mal Coeur 1991;84:108-11.

16. Lenox CC, Debich DE, Zuberbuhler JR. The role of coronary artery abnormalities in the prognosis of truncus arteriosus. J Thorac Cardiovasc Surg 1992;104:1728-40.

17. Bogers AJ, Bartelings MM, Bökenkamp R, et al. Common arterial trunk, uncommon coronary arterial trunk. J THORAC Cardiovasc Surg 1993;106:1133-7.

18. Spicer RL, Behrendt D, Crowley DC, et al. Repair of truncus arteriosus in neonates with the use of a valveless conduit. Circulation 1984;70(Suppl):I26-9.

19. Chan KC, Fype DA, McKay CA, Crawford FA. Right ventricular outflow reconstruction with cryopreserved homografts in pediatric patients: intermediate follow up with serial echocardiographic assessment. J Am Coll Cardiol 1994:24:483-9. 